\title{
Lateral buckling of non-trenched high temperature pipelines with pipelay imperfections
}

\author{
Zhao Tianfeng ${ }^{1}$, Duan Menglan ${ }^{1 *}$, Pan Xiaodong ${ }^{2}$ and Feng Xianhong ${ }^{2}$ \\ ${ }^{1}$ Offshore Oil/Gas Research Center, China University of Petroleum, Beijing 102249, China \\ ${ }^{2}$ Offshore Oil Engineering Ltd., Tanggu, Tianjin 300452, China \\ (C) China University of Petroleum (Beijing) and Springer-Verlag Berlin Heidelberg 2010
}

\begin{abstract}
An analysis method for the buckling process of a pipe section with a random pipelay imperfection is proposed. Four basic lateral modes, acquired by finite-element (FE) eigenvalue buckling analysis, are combined to provide the needed grid configurations for describing a real pipelay imperfection and an arc-length algorithm is used to analyze the snap-through process of the shell-element-grid model under nonlinear frictional boundary conditions. This paper also presents evaluation methods for the lateral buckling of two types of pipe-in-pipe systems that are used in the offshore oil and gas industry. For evaluating the buckling and postbuckling of compliant pipe-in-pipe systems FE analyses were carried out to judge the occurrence of the system buckling and furthermore to check postbuckling stresses induced in the buckles. The calculated results of the modified Riks algorithm indicate that only when high temperature would not trigger an abrupt short-wavelength buckle and when no yielding has been induced in the unavoidable long-wavelength buckles, the thermal stability and safety of compliant pipe-in-pipe systems can be proved. In the non-compliant pipe-in-pipe systems, firstly small-amplitude buckles of the carrier pipe may occur in the annulus between carrier pipe and casing pipe and the contact forces between the spacers and the casing pipe may drive the buckle of the pipe-in-pipe systems on the seabed. Based on the classical analytical solution of pipe buckling, four potential buckling modes corresponding to finiteelement models are developed to evaluate the stability and the postbuckling strength of such pipe-in-pipe systems.
\end{abstract}

Key words: Lateral buckling, postbuckling, pipe-in-pipe systems, modified Riks method, buckling modes

\section{Introduction}

High-temperature submarine pipelines are buried in the seabed to avoid lateral buckling induced by thermal loads, but for those laid on the rocky seabed or in deep water where trenching is difficult and expensive, thermal stability and postbuckling strength should be evaluated by a reliable method. Thermal buckling response of a non-trenched single pipeline was first studied by Hobbs (1984) in a classic paper, the conclusion of which has been widely used subsequently in industry. Taylor and Gan (1986) introduced pipelay imperfections in their analytical solutions. Ose et al (1999) developed the finite-element (FE) model to analyze in-situ behavior of offshore pipelines on an uneven seabed. Previous research aimed at presenting the critical buckling loads of submarine pipelines and suggested avoiding buckling by increasing stiffness and constraints or reducing pipelay imperfections (Hobbs and Liang, 1989; Choi, 1995; Taylor and Tran, 1996). In fact, the natural tendency of a pipeline is to relieve the high resultant axial forces in the pipe-

*Corresponding author. email: mlduan@cup.edu.cn

Received December 30, 2008 wall by buckling and a far more elegant and cost-effective solution is to work with rather than against the pipeline by controlling the lateral buckle formation along the pipeline. A new security principle was proposed by the Joint Industry Project, entitled 'The safe design of hot on-bottom pipelines with lateral buckling' (launched by Boreas Consultants, TWI and Cambridge University, 2006), in which moderate lateral buckling is not only acceptable but an attractive design solution for relief of axial compressive force in hot pipelines (Bruton et al, 2005). Moreover, the buckling is acceptable or not, depending on whether the bending stresses induced in the snap-through process would cause yielding, so an entire lateral buckling evaluation should not only include the estimation of buckling occurrence but also the evaluation of postbuckling pipe stresses and the influence of pipelay imperfections.

On the other hand, current high-temperature projects widely employ pipe-in-pipe (PIP) systems, which can generally be divided into two categories, namely, compliant and non-complaint systems. The compliant systems have connections between the carrier pipe and the casing pipe at close intervals by tulips or donut plates which can act as water-stops and allow the transfer of bending moment 
between the carrier pipe and the casing pipe. In noncomplaint systems, the carrier pipe is connected to the casing pipe by bulkheads, which have high stiffness and be welded at an interval of a few kilometers. In addition, spacers or centralizers are used to prevent contact of the carrier pipe and the casing pipe in the annular space of those systems. Actually the buckling and postbuckling of the pipe-in-pipe systems are more complex than that of a single pipe, so even following a lot of simplifications, it is difficult to find an effective analytical solution to describe the buckling performance of pipe-in-pipe systems in service (Vaz and Patel, 1999), and there has been no widely accepted method yet published for evaluating the lateral buckling of pipe-in-pipe systems.

For the non-trenched single pipeline lateral buckling is preferred over vertical buckling and the configuration of the lateral buckling is governed by three parameters: the axial force in the pipeline, out-of-straightness features (pipeline lay imperfections), and lateral constraints. Although only three parameters are involved, for each parameter several uncertainty factors are included and a precise evaluation on the pipeline buckling still faces many difficulties.

For non-compliant systems, because the bulkheads are a few kilometers apart the connection forces would never be big enough vertically or laterally to drive a buckle with a wavelength of a few kilometers. However the carrier pipe may buckle in the annular space of the pipe-in-pipe systems and considerable bending stress would be induced in the carrier pipe, when the contact forces between the spacers and the casing pipe may drive the pipe systems bending on the seabed.

This paper aims at providing a practical method for evaluating the lateral buckling of a non-trenched single pipe with random lay imperfections and also at presenting evaluation methods for two typical pipe-in-pipe systems, which are also non-trenched.

\section{Buckling evaluation of the single pipe}

Buckle modes extracted by eigenvalue buckling prediction can be applied to configuring the pipelay imperfections of submarine pipelines, so it is required that the same finite element grid of the pipe section be used for the buckling analysis and the eigenvalue buckling prediction. The eigenvalue buckling prediction looks for the loads for which the model stiffness matrix becomes singular, so that the problem $K^{\mathrm{MN}} v^{\mathrm{M}}=0$ has nontrivial solutions. $K^{\mathrm{MN}}$ is the tangent stiffness matrix when the loads are applied and the $v^{\mathrm{M}}$ are the nontrivial displacement solutions. The applied loads consist of pressures, concentrated forces, nonzero prescribed displacements, and/or thermal load. Eigenvalue buckling is generally used to estimate the critical buckling loads of stiff structures. Stiff structures carry their design loads primarily by axial or membrane action, rather than by bending action, so their response usually involves very little deformation prior to buckling. A simple example of a stiff structure is the Euler column, which responds very stiffly to a compressive axial load until a critical load is reached, when it bends suddenly and exhibits a much lower stiffness. However, even when the response of a structure is nonlinear before collapse, a general eigenvalue buckling analysis can provide useful estimates of collapse mode shapes.

In simple cases, linear eigenvalue analysis may be sufficient for design evaluation; but if there is concern about material nonlinearity, geometric nonlinearity prior to buckling, or unstable postbuckling response, a load-deflection analysis must be performed to investigate the problem further. The Riks method (Riks, 1979) uses the load magnitude as an additional unknown; it solves simultaneously for loads and displacements. Therefore, another quantity must be used to measure the progress of the solution; the Riks algorithm uses the 'arc length' along the static equilibrium path in loaddisplacement space. If the Riks step is a continuation of a previous history, any loads that exist at the beginning of the step and are not redefined are treated as 'dead' loads with constant magnitude. A load whose magnitude is defined in the Riks step is referred to as a 'reference' load. The current load magnitude $P_{\text {total }}$ which is defined by $P_{\text {total }}=P_{0}+\lambda\left(P_{\text {ref }}-P_{0}\right)$, where $P_{0}$ is the 'dead load', $P_{\text {ref }}$ is the reference load vector, and $\lambda$ is the load proportionality factor (LPF). The load proportionality factor is found as part of the solution. The Riks algorithm provides the current value of the load proportionality factor at each increment.

Normally the pipeline would penetrate in the seabed, so the forces required to move the pipeline laterally become larger than the forces required to move it in the longitudinal direction. This effect is due to the passive lateral soil resistance that is produced when a wedge of soil resists the pipe's motion. An anisotropic friction model that defines different friction coefficients in the lateral and longitudinal directions of the pipeline allows this effect to be investigated. Brennodden (1991) raised the pattern of resistance change when the pipeline moves laterally on the seabed, and defined the breakout force as the maximum force required to move the pipe from its stable position which was significantly higher than that required to maintain the movement after breakout due to suction and extra force needed for the pipe to 'climb' out of its depression. Verley and Lund (1995) put forward the following formula to calculate pipeline penetration in the seabed, which was suitable for pipelines with an external diameter of $0.2-1.0 \mathrm{~m}$, resting on clays with undrained shear strength of $0.8-70 \mathrm{kPa}$.

$$
\frac{z}{D}=0.0071\left(S \cdot G^{0.3}\right)^{3.2}+0.062\left(S \cdot G^{0.3}\right)^{0.7}
$$

with

$$
\begin{aligned}
& S=F_{\mathrm{v}} /\left(D \cdot S_{\mathrm{u}}\right) \\
& G=S_{\mathrm{u}} /\left(D \cdot \gamma^{\prime}\right)
\end{aligned}
$$

where $z$ is the pipe penetration, mm; $D$ is the pipe external diameter, $\mathrm{mm} ; F_{\mathrm{v}}$ is the vertical contact force, $\mathrm{kN} / \mathrm{m} ; S_{\mathrm{u}}$ is the undrained shear strength, $\mathrm{kPa} ; \gamma^{\prime}$ is the submerged soil density, $\mathrm{kN} / \mathrm{m}^{3}$.

A model recalibrated by Bruton et al (2006) is about pipesoil interaction behavior during lateral buckling based on the new database and the following expression was derived for 
breakout resistance:

$$
\frac{H_{\text {breakout }}}{S_{\mathrm{u}} \cdot D}=0.2 \frac{F_{\mathrm{v}}}{S_{\mathrm{u}} \cdot D}+\frac{3}{\sqrt{\frac{S_{\mathrm{u}}}{\gamma^{\prime} D}}} \cdot \frac{z}{D}
$$

where $H_{\text {breakout }}$ is the maximum lateral resistance as buckling occurs, $\mathrm{kN} / \mathrm{m}$.
For FE analyses of pipeline buckling evaluation, spring elements can be used to simulate sea floor friction restraints, and spring forces of which can be defined as a nonlinear variable of pipeline movement displacement. Fig. 1 provides the buckling evaluation method developed in this paper, and the combination of several algorithms is employed to acquire a reliable evaluation result of pipeline buckling.

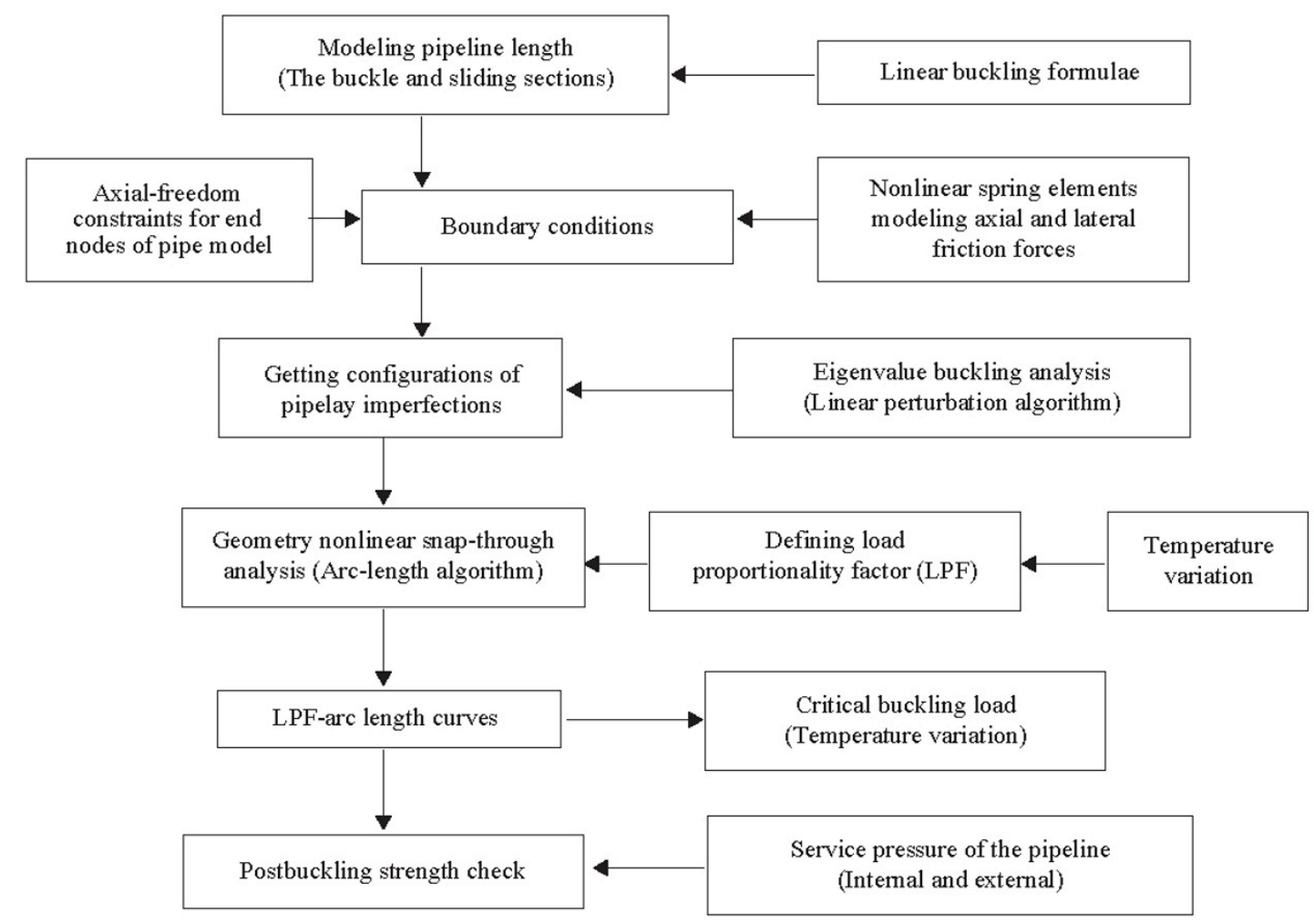

Fig. 1 A nonlinear FE method for analyzing pipeline buckling

In fact, a real pipelay imperfection can never be known prior to pipelay, so it is necessary to evaluate the buckling of a pipe section with a random imperfection, especially for such high-temperature solution measures as pre-heating and snakelay. The following provides a feasible method for precisely evaluating lateral buckling of a pipe section with a random imperfection. As an illustration, the configuration of the pipe imperfection is assumed as shown in Fig. 2 and the typically assumed base data of the pipeline are listed in Table 1.

First of all a mode analysis needs to be carried out and the imperfection configuration can be seen as a superposition of the configurations of four Hobbs' lateral modes (shown in Fig. 9). So the above configuration can be decomposed into four $100 \mathrm{~m}$-wavelength configurations: a first-order configuration with $2.0 \mathrm{~m}$ amplitude, a second-order configuration with $2.0 \mathrm{~m}$ amplitude, a third-order configuration with $2.0 \mathrm{~m}$ amplitude, and a fourth-order configuration with $2.0 \mathrm{~m}$ amplitude. These base configurations can be acquired by FE eigenvalue buckling analysis for a certain pipe section and by grid perturbation technique, and an initial imperfect configuration as in the above example can be constructed for the following snap-through analysis

According to the Hobbs lateral buckling theory amongst others, the sliding length of the first-order buckle is longer

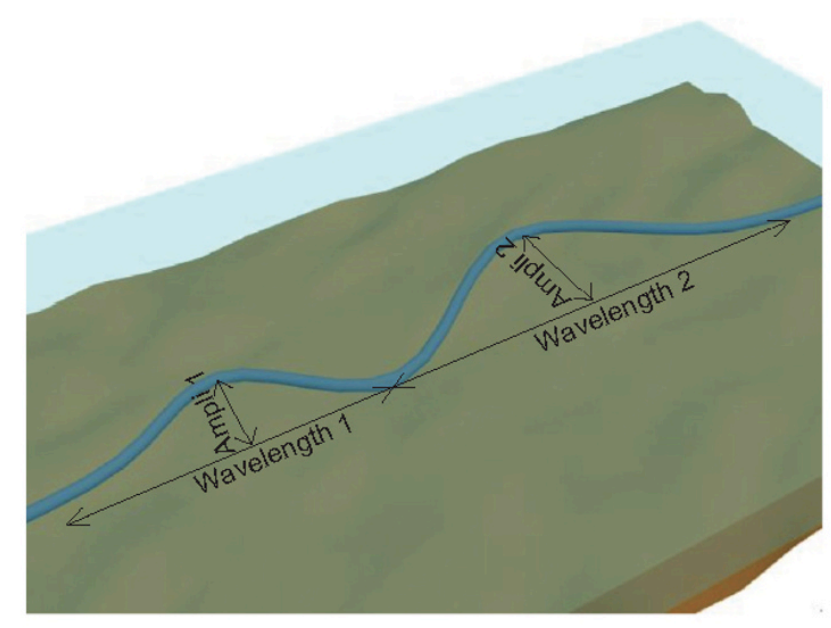

Fig. 2 A possible imperfection configuration in practice

than those of the other three modes, so a random buckle with a superposition configuration would have a sliding length shorter than that of first-order mode buckle. Therefore, the simulation range needed to entirely describe the buckling process of the pipe section shown in Fig. 2 can be decided conservatively by calculating the sliding length of the firstorder buckle, whose buckle length is the sum of Wavelength 
1 and Wavelength 2. Based on the Hobbs formulae the sliding length can be calculated by the axial force depression in the buckle and for the above example the result is $680 \mathrm{~m}$ when the friction coefficient is selected as 0.5 , so a $1,460 \mathrm{~m}$ (buckle length and two sliding sections beside) simulating range is needed to analyze the buckling of Fig. 2 pipe section, conservatively.

In buckling analysis (the modified Riks algorithm was used), the load proportionality factor is defined by a temperature increment of $50{ }^{\circ} \mathrm{C}$ and the nonlinear friction boundary conditions are modeled by defining the nonlinear relationships between the related nodes displacement of pipe model and the reactions of attached spring elements.

Analysis results of three typical buckling phases are listed in Table 2. These results indicate that the single pipeline with an initial imperfection (Fig. 2) can keep its axial supporting capability even a buckle laterally induced in the imperfection section (phase-1), and loses its axial supporting capability until the perfect section of the pipeline buckling (phase-2). Finally if the thermal load continues increasing buckling failure firstly may be induced in the imperfection section (phase-3).

Analysis results in Table 2 also reveal that the pipeline can keep its stability on the seabed and the stress concentration induced in the buckle of the imperfection section is still acceptable when the thermal load is less than $43.3{ }^{\circ} \mathrm{C}$. At the same time the axial pipe displacement towards the buckle has released the axial force in this hot pipeline to some extent. The viewpoints of the Joint Industry Project can be proved in this illustration that the lateral buckling can be utilized to release axial force in a hot pipeline without inducing buckling failure if suitable and enough imperfections are introduced by buckle initiation technologies such as snake-lay, vertical upset, and distributed buoyancy.

Table 1 Base data of the submarine pipeline with a pipelay imperfection as Fig. 2 shown

\begin{tabular}{|c|c|c|c|}
\hline Outside diameter, mm & 273.1 & Expansion coefficient, $1 /{ }^{\circ} \mathrm{C}$ & $1.17 \times 10^{-5}$ \\
\hline Wall thickness, mm & 11.1 & Pipe submerged weight, N/m & 1709 \\
\hline Pipe material & API 5L X65 carbon steel & Minimum friction & $0.3 \times$ submerged weight \\
\hline Young's modulus, MPa & 207000 & Maximum friction & $H_{\text {breakout }}$ \\
\hline Poisson's ratio & 0.3 & \multirow{2}{*}{ Pipelay imperfection } & Wavelength $1=43.0 \mathrm{~m}$, Amplitude $1=3.0 \mathrm{~m}$ \\
\hline Content density, $\mathrm{kg} / \mathrm{m}^{3}$ & 720 & & Wavelength $2=57.0 \mathrm{~m}$, Amplitude $2=5.3 \mathrm{~m}$ \\
\hline
\end{tabular}

Table 2 Three typical buckling phases of the example listed in Table 1

\begin{tabular}{cccc}
\hline \multicolumn{1}{c}{ Analysis results of Riks algorithm } & Phase-1 & Phase-2 & 10.54 \\
\hline \multicolumn{1}{c}{ Arc length } & 0.175 & 12.69 \\
LPF value (thermal load $\Delta T)$ & $0.091399\left(4.6^{\circ} \mathrm{C}\right)$ & $0.866207\left(43.3^{\circ} \mathrm{C}\right)$ & $1.98281:\left(99.1^{\circ} \mathrm{C}\right)$ \\
Bending stresses (Mises values), MPa & 15.2 & 144.3 & 329.6 \\
Maximum lateral displacement of the buckle, $\mathrm{m}$ & $7.39 \times 10^{-3}$ & 0.260 & 0.730 \\
Maximum axial displacement towards the buckle, $\mathrm{m}$ & $9.69 \times 10^{-3}$ & 0.116 \\
\hline
\end{tabular}

Notes: Phase-1: Pipe section with initial imperfection buckling;

Phase-2: Perfect section outside initial imperfection buckling;

Phase-3: Possible failure of initial imperfection section

\section{Buckling evaluation of compliant PIP systems}

The following example analyzed can be used to illustrate the evaluation method for the buckling of compliant pipe-inpipe (PIP) systems. First of all the pipeline data are assumed as follows. The outside diameter and wall thickness of the carrier pipe are $323.85 \mathrm{~mm}$ and $11.1 \mathrm{~mm}$, respectively; and their values of the casing pipe are $457.2 \mathrm{~mm}$ and $11.1 \mathrm{~mm}$. The materials of the carrier and casing pipes are API 5L X65 carbon steel and API 5L X56 carbon steel respectively, with Young's modulus of 207,000 MPa, Poisson's ratio of 0.3 , and an expansion coefficient of $1.17 \times 10^{-5} 1 /{ }^{\circ} \mathrm{C}$. The PIP systems are insulated by polyurethane foam (PUF) of a minimum density $96 \mathrm{~kg} / \mathrm{m}^{3}$. The stiffness of the PUF can be neglected during buckling process. The submerged weight of the pipein-pipe systems is $1,003 \mathrm{~N} / \mathrm{m}$.

To evaluate the snap-through and postbuckling of the compliant PIP systems, $121.92 \mathrm{~m}$ (ten simple roots) and $182.88 \mathrm{~m}$ (fifteen simple roots) pipeline sections are selected. These are exactly located in three and four groups of donut plates. Four-node shell elements (S4R) are used to model the pipeline like evaluating the single pipe buckling and the coupling constraints are applied to simulating the donut 
plate connections between the carrier and casing pipes. Spring element forces are utilized to describe seabed friction forces which are defined as nonlinear variables of movement displacements and here the lateral friction coefficient between the pipeline and the seabed is selected as 0.5 and the axial friction coefficient is selected as 0.3 . To conservatively evaluate the thermal snap-through process of pipe-in-pipe systems, pipelay imperfections can be assumed possessing the configurations like those of the buckles of PIP systems and the analysis results of eigenvalue buckling prediction would be used to perturb the perfect grid.

\subsection{Buckling process of pipeline section within three groups of donut plates}

By eigenvalue buckling analysis (linear perturbation algorithm) the buckling modes of the section within three groups of donut plates are discussed. During analysis only the thermal load is considered and the prior three modes on the seabed plane are extracted as eigenvectors (whose maximum lateral displacements have been normalized to 1.0, shown in Fig. 3). The configuration of the second mode is selected as pipelay imperfection to be introduced into the FE model grid.

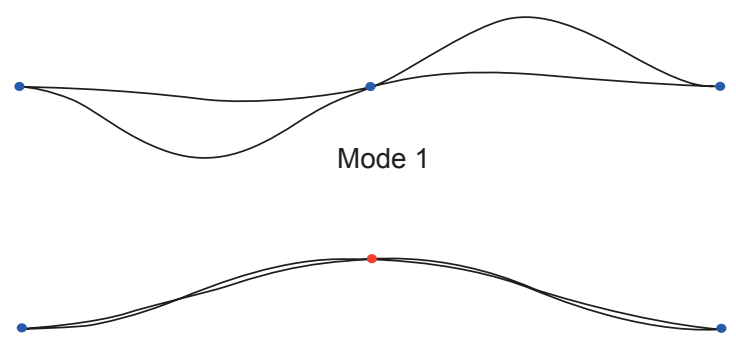

Mode 2

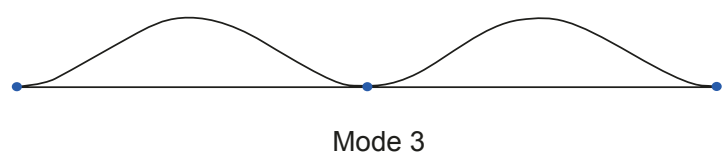

Fig. 3 Three lateral buckling modes of PIP systems (121.92 m section model)

In the buckling process analysis (the modified Riks algorithm), the axial displacement of one group of donut plates is used as the analytical load and at each increment the load proportionality factor is defined taking a $0.1 \mathrm{~m}$ axial displacement as a reference load. For different geometric imperfections introduced (scaling factors are selected as $0.05,0.15$, and 0.2 , so the maximum amplitudes of pipelay imperfections introduced are respectively $0.05,0.15$ and 0.20 m) a plot of arc length versus load proportionality factor is given in Fig. 4. Two inflection points on the arc length-LPF curves reveal the buckling process of PIP systems. The first inflection point indicates the buckling of the carrier pipe in the annular space of the PIP systems and the second indicates the bending deformation of the casing pipe when the PIP systems buckle as a whole.

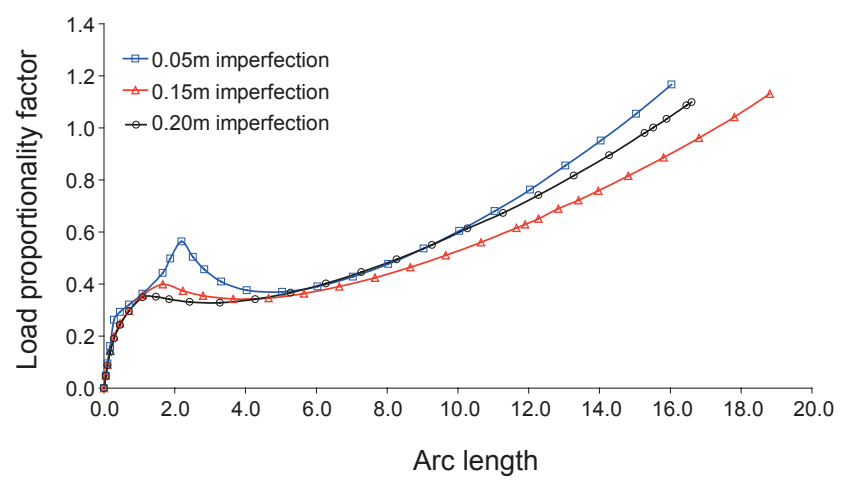

Fig. 4 Arc length vs. LPF curves for lateral buckling process of PIP systems (121.92 m section model)

Fig. 5 provides a plot of the maximum lateral displacement vs. axial force curves for the buckling of PIP systems, of which only one inflection point indicates that the casing pipe begins to buckle under axial loading and for the $121.92 \mathrm{~m}$ pipeline approximately $2.0 \mathrm{~m}$ lateral displacement occurs in the postbuckling process. Fig. 5 also reveals that a more perfect pipe section has a higher stiffness against lateral buckling while its buckling process is a more sudden snapthrough process causing more noticeable stress concentration in the buckle.

For different pipelay imperfections introduced, Table 3 provides comparisons of the critical buckling loads, the critical buckling temperatures, the critical axial forces on the donut plates, and the maximum Mises stresses induced in the buckles.

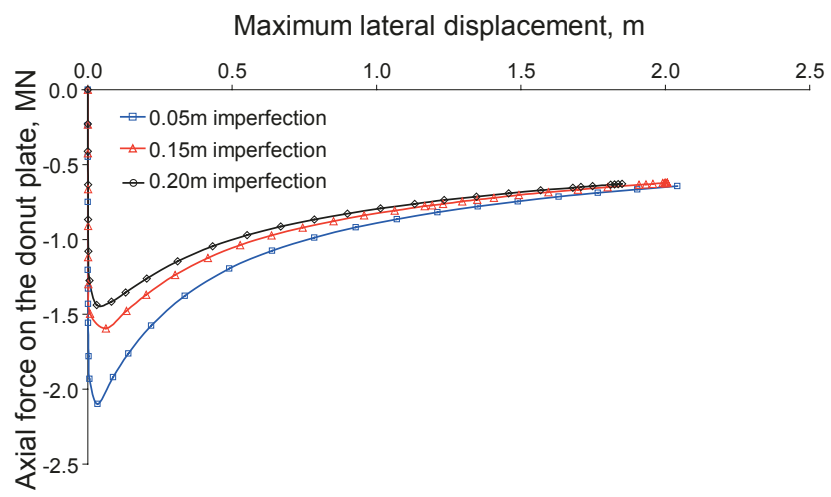

Fig. 5 Maximum lateral displacement vs. axial force curves for lateral buckling of PIP systems (121.92 m section model)

\subsection{Postbuckling process of pipeline section within four groups of donut plates}

Postbuckling evaluation of compliant PIP systems was carried out by analyzing postbuckling performance of a section within four groups of donut plates. Fig. 6 shows that the prior four modes normalized and the configuration of the first mode was used to introduce pipelay imperfection to the FE model of PIP systems. 
Table 3 Stresses induced in the buckles of compliant PIP systems as lateral buckling occurs (121.92 m section model)

\begin{tabular}{ccccc}
\hline $\begin{array}{c}\text { Imperfection } \\
\mathrm{m}\end{array}$ & $\begin{array}{c}\text { Critical } \\
\text { Displacement } \\
\text { loads, } \mathrm{m}\end{array}$ & $\begin{array}{c}\text { Critical axial } \\
\text { forces } \\
\mathrm{MN}\end{array}$ & $\begin{array}{c}\text { Critical } \\
\text { temperature rise } \\
{ }^{\circ} \mathrm{C}\end{array}$ & $\begin{array}{c}\text { Maximum Mises stress in the } \\
\text { carrier pipe buckle } \\
\text { MPa }\end{array}$ \\
\hline 0.05 & 0.0563 & 2.099 & 112.5 & 186.3 \\
0.15 & 0.0399 & 1.594 & 85.4 & 134.0 \\
0.20 & 0.0349 & 1.438 & 77.1 & 117.6 \\
\hline
\end{tabular}

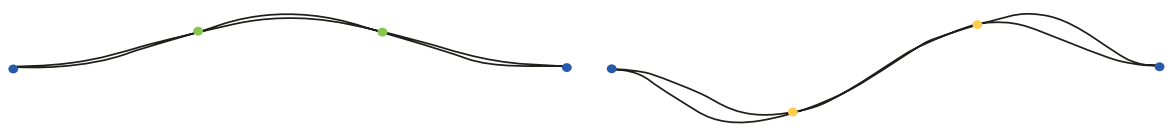

Mode 1

Mode 2

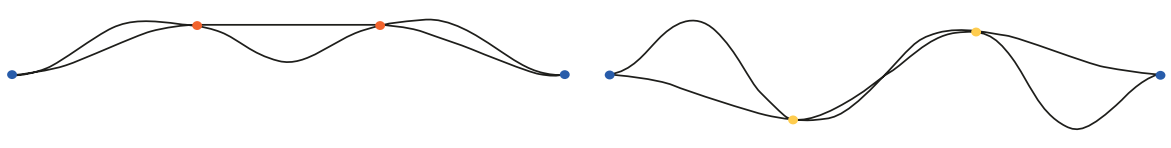

Mode 3

Mode 4

Fig. 6 Four lateral buckling modes of PIP systems (182.88 m section model)

For the postbuckling analysis the axial displacement of one group of donut plates is also used as analytical load and for different imperfections introduced (scaling factors are selected as $0.01,0.06$, and 0.1 , so the maximum amplitudes of imperfections introduced are respectively $0.01,0.06$ and 0.10 $\mathrm{m})$ a plot of arc length versus load proportionality factor is shown in Fig. 7, and a plot of maximum lateral displacement versus axial force is presented in Fig. 8.

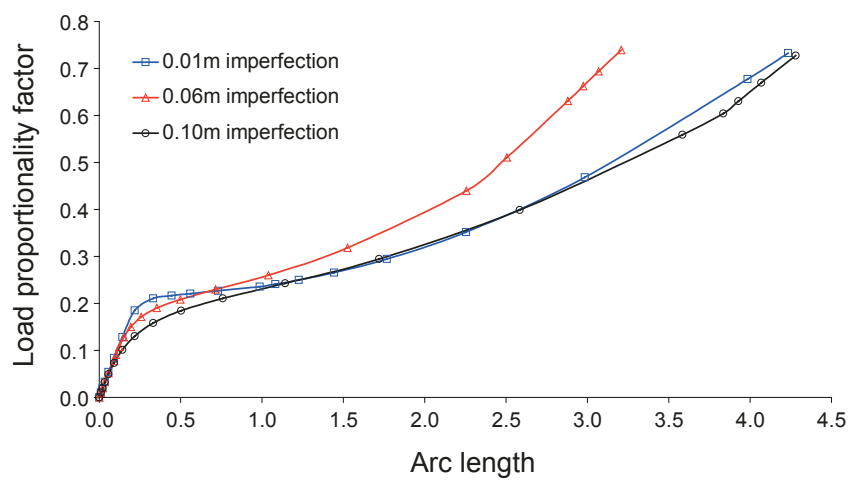

Fig. 7 Arc length vs. LPF curves for postbuckling of PIP systems (182.88 m section model)

Figs. 7 and 8 indicate that a $182.88 \mathrm{~m}$ pipe section of a compliant PIP system buckles at a low critical axial force and a buckle within four groups of donut plates must appear under service thermal load. For this reason it is important to check the postbuckling strength of compliant PIP systems even though pipelay imperfections have a tiny influence on the occurrence of long wavelength buckles. Table 4 provides comparisons of the maximum stresses induced when lateral buckling occurs and Table 5 lists the maximum postbuckling stresses induced in the buckle when $70{ }^{\circ} \mathrm{C}$ service temperature is applied.

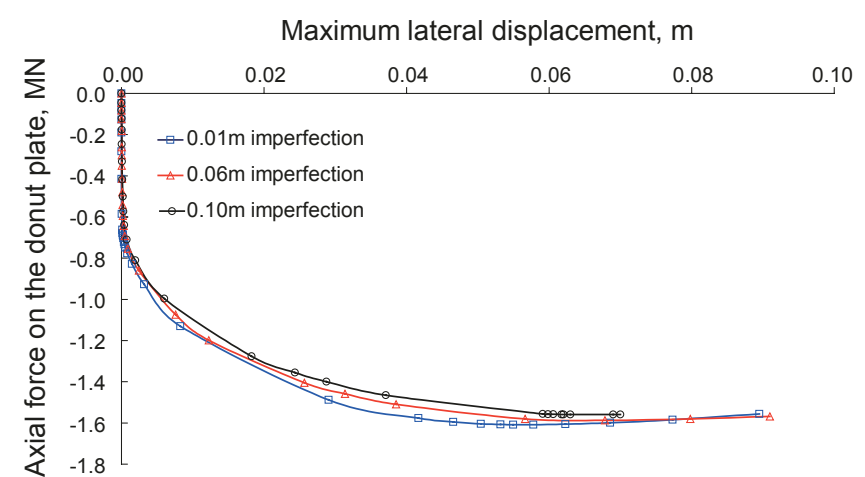

Fig. 8 Maximum lateral displacement vs. axial force curves for postbuckling process of PIP systems (182.88 m section model)

Based on the analysis results mentioned above, the conclusion can be drawn that reliable compliant PIP systems need to avoid destructive short-wavelength buckles and at the same time meet the postbuckling strength requirements of the inevitable long-wavelength buckles.

\section{Buckling evaluation of non-compliant PIP systems}

The buckling of non-compliant PIP systems typically begins with the occurrence of carrier pipe buckles in the annular space, and such buckles resemble the buckles of a single pipe except that the maximum amplitude of the buckle of carrier pipe is confined by the clearance in the annular space of non-compliant PIP systems. However, contact forces may be induced between the spacers and the casing pipe in the annular space and these then cause the system to buckle on the seabed if the frictional resistance is overcome. In practice the reserved clearance of the annular space is $4-10$ 
Table 4 Stresses induced in the buckles of compliant PIP systems as lateral buckling occurs (182.88 m section model)

\begin{tabular}{cccccc}
\hline $\begin{array}{c}\text { Imperfection Critical displacement } \\
\text { loads, } \mathrm{m}\end{array}$ & $\begin{array}{c}\text { Critical axial } \\
\text { forces, } \mathrm{MN}\end{array}$ & $\begin{array}{c}\text { Critical temperature } \\
\text { rise, }{ }^{\circ} \mathrm{C}\end{array}$ & $\begin{array}{c}\text { Maximum Mises stress in the } \\
\text { carrier pipe buckle, MPa }\end{array}$ & $\begin{array}{c}\text { Maximum Mises stress in the } \\
\text { casing pipe buckle, MPa }\end{array}$ \\
\hline 0.01 & 0.0211 & 0.6621 & 35.5 & 30.66 & 28.58 \\
0.06 & 0.0171 & 0.5406 & 29.0 & 28.11 & 24.64 \\
0.10 & 0.0159 & 0.5004 & 26.8 & 28.23 & 23.92 \\
\hline
\end{tabular}

Table 5 Maximum stress induced in the postbuckling process of compliant PIP systems

(182.88 $\mathrm{m}$ section model, $70{ }^{\circ} \mathrm{C}$ operation temperature applied)

\begin{tabular}{ccc}
\hline $\begin{array}{c}\text { Imperfection } \\
\mathrm{m}\end{array}$ & $\begin{array}{c}\text { Maximum Mises stress in the } \\
\text { carrier pipe buckle, MPa }\end{array}$ & $\begin{array}{c}\text { Maximum Mises stress in the } \\
\text { casing pipe buckle, MPa }\end{array}$ \\
\hline 0.01 & 116.9 & 123.9 \\
0.06 & 115.6 & 121.2 \\
0.10 & 115.3 & 120.8 \\
\hline
\end{tabular}

$\mathrm{mm}$, so the initial buckle in the annular space is a small-slope one and can be analyzed by the classical Hobbs formulae. The following example is provided to illustrate an evaluation method for the buckling of non-compliant PIP systems.

The outside diameter and wall thickness of the carrier pipe are 273.1 and $12.7 \mathrm{~mm}$, respectively. The material of the carrier pipe is API 5L X65 carbon steel with Young's modulus of 207,000 MPa, Poisson's ratio of 0.3 and an expansion coefficient of $1.17 \times 10^{-5} 1 /{ }^{\circ} \mathrm{C}$. The outside diameter and wall thickness of the casing pipe are $355.6 \mathrm{~mm}$ and 11.1 $\mathrm{mm}$, respectively, and the material of the casing pipe is API

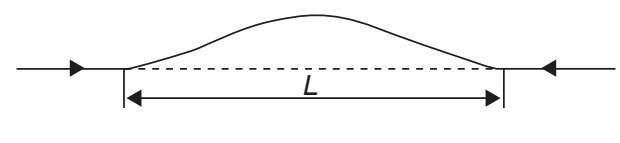

Mode 1

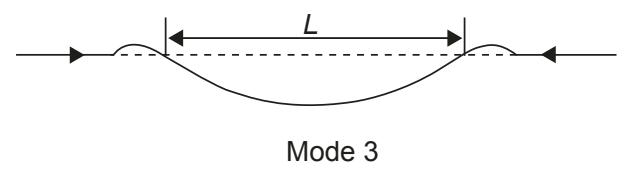

5L X60 carbon steel. The reserved clearance in the annular space is $8 \mathrm{~mm}$ and the friction coefficient in the annular space is selected as 0.22 .

Hobbs defined four lateral modes for single pipe buckling on the seabed, the configurations of which are shown in Fig. 9. According to Hobbs' theory, the critical axial forces, the maximum amplitudes, and the bending moments of these buckles can be calculated by the following equations:

$$
\begin{aligned}
& p_{0}=k_{1} \frac{E I}{L^{2}}+k_{3} \varphi \omega L\left[\left(1.0+k_{2} \frac{A E \varphi \omega L^{5}}{(E I)^{2}}\right)^{1 / 2}-1.0\right] \\
& \hat{y}=k_{4} \frac{\varphi \omega}{E I} L^{4} \\
& \hat{M}=k_{5} \varphi \omega L^{2}
\end{aligned}
$$

where $L$ is the length of the buckle, m; $I$ is the second moment of area of the cross section, $\mathrm{m}^{4} ; E$ is Young's modulus of steel pipe, $\mathrm{MPa} ; \omega$ is the submerged weight of the pipeline (including the weight coat) per unit length, $\mathrm{N} / \mathrm{m} ; \varphi$ is the coefficient of friction between seabed and pipeline; $A$ is the cross-sectional area of pipeline, $\mathrm{m}^{2}$; and $k_{1}$ through $k_{5}$ are constants and their values are listed in Table 6.

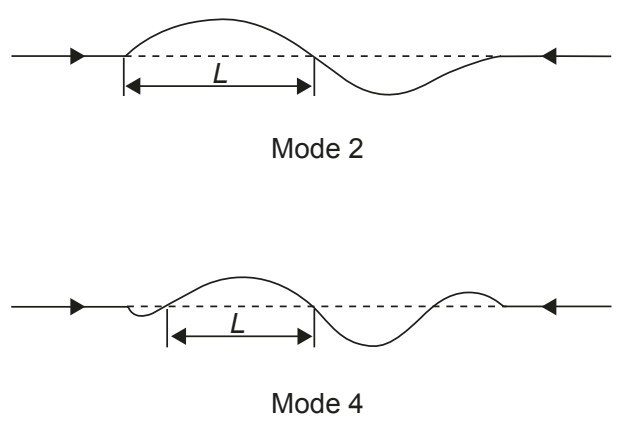

Fig. 9 Typical lateral buckling modes and definitions of buckle lengths

Table 6 Constants for lateral buckling modes

\begin{tabular}{cccccc}
\hline Mode & $k_{1}$ & $k_{2}$ & $k_{3}$ & $k_{4}$ & $k_{5}$ \\
\hline 1 & 80.76 & $6.39 \times 10^{-5}$ & $0.5:$ & $2.41 \times 10^{-3}$ & 0.069 \\
2 & $4 \pi^{2}$ & $1.74 \times 10^{-4}$ & 1.0 & $5.53 \times 10^{-3}$ & 0.109 \\
3 & 34.06 & $1.67 \times 10^{-4}$ & 1.294 & $1.03 \times 10^{-2}$ & 0.143 \\
4 & 28.20 & $2.14 \times 10^{-4}$ & 1.608 & $1.05 \times 10^{-2}$ & 0.148 \\
$\infty$ & $4 \pi^{2}$ & $4.70 \times 10^{-5}$ & $4.70 \times 10^{-5}$ & $4.45 \times 10^{-3}$ & 0.051 \\
\hline
\end{tabular}


Based on the amplitude of the buckled pipe in the annular space of non-compliant PIP systems, the buckle lengths of the carrier pipe can be calculated from Eq. (4) and then the critical axial forces of four lateral modes can be calculated from Eq. (3). For four lateral modes and infinite mode Fig. 10 gives a plot of the reserved installation clearance versus critical buckling load.

When the installation clearance in the annular space of non-compliant PIP systems is $8 \mathrm{~mm}$ and in the annular space the weight of carrier pipe is $1263.3 \mathrm{~N} / \mathrm{m}$ (with a content density of $900 \mathrm{~kg} / \mathrm{m}^{3}$ ), Table 7 lists the calculated results of buckle lengths, critical axial forces, and maximum bending moments of the buckled carrier pipe. The calculated results in Table 7 can be used as the base of buckling evaluation of noncompliant PIP systems. If the operation temperature of the PIP systems is $97^{\circ} \mathrm{C}$, buckling mode 1 and buckling mode 3 would not be induced in the annular space while the buckling mode 2 and mode 4 would occur. Then FE analysis should be followed to describe an entire buckling process of noncompliant PIP systems.

These buckles in the annular space only have a small slope, so the lengths of sliding sections beside them can be neglected. Therefore, for evaluating the non-compliant PIP system buckling issued from the second-order buckle of the carrier pipe, a $35.12 \mathrm{~m}$ pipeline system is needed to be modeled, and a $59.88 \mathrm{~m}$ pipeline system is needed to be modeled for evaluating the system buckling issued from the fourth-order mode buckle of the carrier pipe. Using grid perturbation technology, configurations of the initial buckling of the carrier pipe need to be introduced to the perfect FE grid to construct the postbuckling analysis model of the systems. Also the modified Riks algorithm can be used to analyze the postbuckling of the non-compliant PIP systems and at the same time the contact definition should be included in the

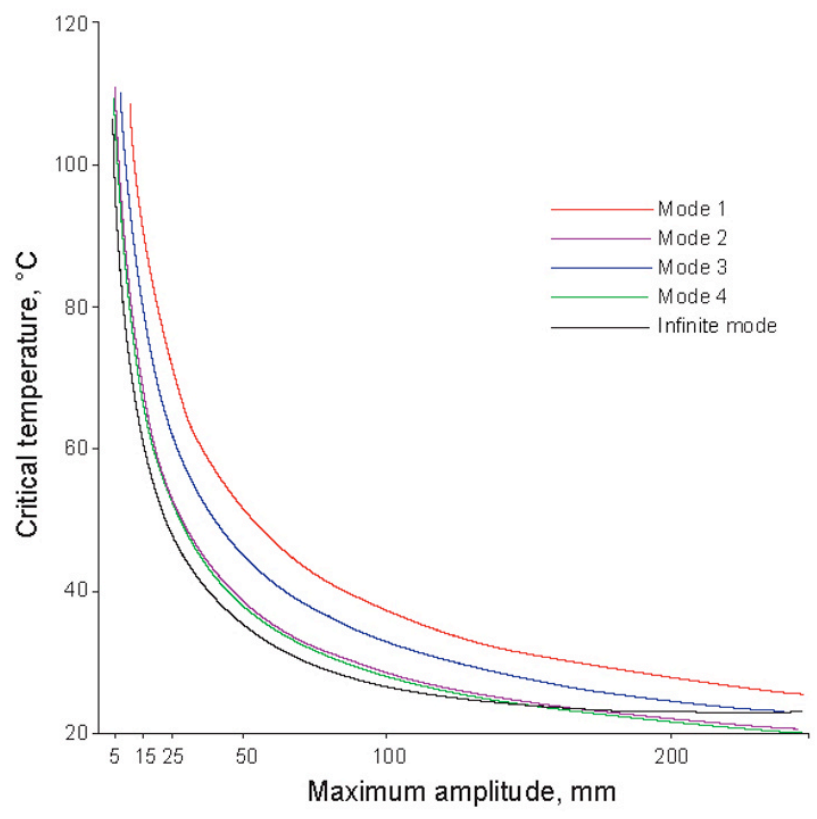

Fig. 10 Reserved installation clearance vs. critical buckling load curves (modes 1-4 and infinite mode)

model.

Analysis results indicate that when the thermal load reaches $97^{\circ} \mathrm{C}$ the second-mode buckle of the carrier pipe produces an axial stress of $285.5 \mathrm{MPa}$ in the postbuckling process and the casing pipe is hardly moved by the contact forces in the annular space of the non-compliant PIP system. Similarly in the postbuckling process the fourth-mode buckle produces an axial stress of $280.6 \mathrm{MPa}$ (the distribution of axial stress of the carrier pipe is shown in Fig. 11) when about $2.6 \mathrm{~mm}$ lateral movement of casing pipe is triggered by the contact forces.

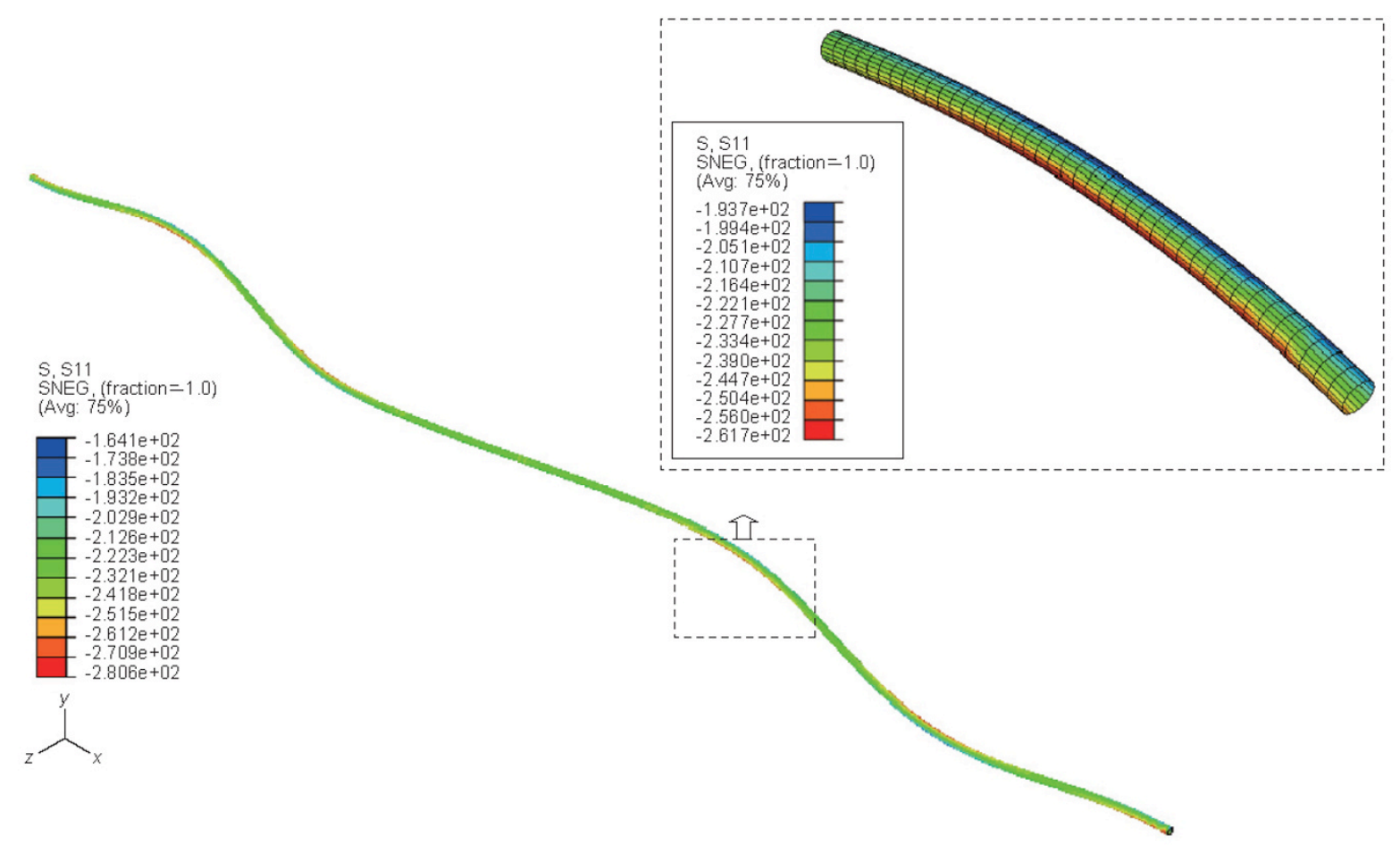

Fig. 11 The distribution of postbuckling axial stress along the carrier pipe under a thermal load of $97^{\circ} \mathrm{C}$ (postbuckling issued from the initial buckle of the fourth-order mode, deformation magnified 50 times) 
Table 7 Critical axial forces, buckle lengths, and maximum bending moments of 1st-4th modes

\begin{tabular}{ccccc}
\hline Mode & $\begin{array}{c}\text { Buckle length } \\
\mathrm{m}\end{array}$ & $\begin{array}{c}\text { Critical axial force } \\
\mathrm{MN}\end{array}$ & $\begin{array}{c}\text { Critical temperature } \\
{ }^{\circ} \mathrm{C}\end{array}$ & $\begin{array}{c}\text { Maximum bending moment } \\
\mathrm{MN} \cdot \mathrm{m}\end{array}$ \\
\hline 1 & 21.62 & 3.158 & 125.5 & $9.02 \times 10^{-3}$ \\
2 & 17.56 & 2.341 & 93.0 & $9.33 \times 10^{-3}$ \\
3 & 15.02 & 2.758 & 109.6 & $9.00 \times 10^{-3}$ \\
4 & 14.97 & 2.300 & 91.4 & $9.24 \times 10^{-3}$ \\
\hline
\end{tabular}

\section{Conclusions}

1) The evaluation of lateral buckling of non-trenched single pipelines includes the effect of pipelay imperfections and the nonlinear frictions except that thermal buckling is a geometry nonlinear snap-through process. Though confined by the assumption of small-slope deformation classical analytical solutions (such as the Hobbs formulae) can guide FE model construction.

2) The snap-through process of a perfect pipe section would be more abrupt and significant stress concentration would be induced in the buckle. Though the buckling of some high-temperature solutions (such as snake-lay, vertical upset, and distributed buoyancy) would be gentle, a postbuckling strength check is also necessary.

3) For evaluating the bucking of non-trenched compliant PIP systems two stages of analysis should be carried out, one for predicting possible short-wavelength buckles and the other for postbuckling strength checking. The systems need to select a reasonable interval to place donut plates to meet the requirements of thermal stability and postbuckling strength of PIP systems.

4) The buckling risk of non-compliant systems is that the carrier pipe buckles in the annular space and severe stress concentration is induced in the carrier pipe buckles. So enough stiffness and installation precision of the PIP systems are necessary to improve the thermal stability of systems.

\section{Acknowledgements}

This work was financially supported by the National Natural Science Foundation of China (No .50979113). The authors are grateful for approval to publish.

\section{References}

Brennodden H. Troll phase 1: verification of expansion curve analysis and consolidation effects: part 1: experimental verification of consolidation effects: Volume 2: Main report. SINTEF Report no. STF69 F91012. 1991. 75

Bruton D, Carr M, Crawford M, et al. The safe design of hot onbottom pipelines with lateral buckling using the design guideline developed by the SAFEBUCK Joint Industry Project. Deep Offshore Technology Conference, 2005, Vitoria, Espirito Santo, Brazil

Bruton D, White D, Cheuk C, et al. Pipe/soil interaction behavior during lateral buckling, including large-amplitude cyclic displacement tests by the safebuck JIP. Offshore Technology Conference, 1-4 May 2006, Houston, Texas (OTC 17944)

Choi H S. Expansion analysis of offshore pipelines close to restraints. Proceedings of the Fifth International Offshore and Polar Engineering Conference. 1995. 2: 81-88. Golden, Colorado, USA

Hobbs R E. In-service buckling of heated pipelines. Journal of Transportation Engineering. 1984. 110(2): 175-189

Hobbs R E and Liang F. Thermal buckling of pipelines close to restraints. Eighth International Offshore Mechanics and Arctic Engineering Symposium. 1989. 5: 121-127. New York, USA

Ose B A, Bai Y, Nystrøm P R, et al. A finite-element model for in-situ behavior of offshore pipelines on uneven seabed and its application to on-bottom stability. Proceedings of the Ninth International Offshore and Polar Engineering Conference. May 30-June 4 1999, Brest, France. 132-140

Riks. An incremental approach to the solution of snapping and buckling problems. International Journal of Solids and Structures. 1979. 15(7): 529-551

Taylor N and Gan A B. Submarine pipeline buckling-imperfection studies. J. Thin Walled Structures. 1986. 4(4): 295-323

Taylor $\mathrm{N}$ and Tran V. Experimental and theoretical studies in subsea pipeline buckling. J. Marine Structures. 1996. 9(2): 211-257

Vaz M A and Patel M H. Lateral buckling of bundled pipe systems. J. Marine Structure. 1999. 12(1): 21-40

Verley R and Lund K M. A soil resistance model for pipelines placed on clay soils. Proceedings of International Conference on Offshore Mechanics and Arctic Engineering. 1995. 5: 225-232. Pipeline Technology, Copenhagen, Denmark

(Edited by Sun Yanhua) 